Proc. Indian Acad. Sci. (Earth Plane1. Sci.), Vol. 90, No. 3, November 1981, pp. 263-271.

C) Printed in India.

\title{
Atmospheric temperature profile for a tropical region from TIROS-N microwave sounding unit
}

\author{
B S GOHIL, A K SHARMA and P C PANDEY \\ Meteorology Division, Space Applications Centre (ISRO), \\ Ahmedabad 380 053, India
}

MS received 18 November 1980; revised 6 July 1981

\begin{abstract}
Atmospheric temperature profiles have been derived using $53.74 \mathrm{GHz}, 54.96$ $\mathrm{GHz}$ and $57.95 \mathrm{GHz}$ channels data from the Microwave Sounding Unit onboard TIROS-N. For this purpose regression coefficients have been derived using MONEX-79 radiosonde data during the period May to July 1979. The temperature profiles derived at a few selected places were closer to radiosonde profiles than the profiles derived using standard regression coefficients for the tropical region supplied by NOAA.
\end{abstract}

Keywords. Atmospheric temperature profile; statistical regression method; tropics.

\section{Introduction}

The microwave sounding unit (MSU) is one of the three TIROS-N Operational Vertical Sounder (TOVS) sensors. It enables derivation of atmospheric temperature profiles using the oxygen absorption band channels at 50.30, 53.74, 54.96 and $57.95 \mathrm{GHz}$. These frequencies have board weighting functions which peak at 1000,600,300 and 60 millibar levels respectively. Preliminary studies were carried out to derive temperature profile using regression coefficients supplied by NOAA which refer to large grid size $30^{\circ} \mathrm{N}$ to $30^{\circ} \mathrm{S}$.

In the present paper, regression coefficients have been derived with MONEX-79 data sets from simulations, using method described by Waters et al (1975). These coefficients gave temperature profiles in better agreement with those from radiosonde data.

\section{Retrieval of temperature profile}

The TOVS data from TIROS-N received via VHF telemetry was first preprocessed for demultiplexing, calibration and earth location (NOAA 1978, 1979). Also limb correction and correction due to cloud contamination, surface effects, antenna pattern, etc. were performed based on correction coefficients supplied by NOAA. 


\subsection{Weighting functions for MSU chamels}

The radiative transfer equation describing the intensity of radiation emerging from the atmosphere can be written in terms of brightness temperature as

$$
\begin{aligned}
& T_{\mathrm{B}}(\nu)=L_{\nu}(0, \infty) \cdot T_{\mathrm{B}} \epsilon_{\mathrm{B}}(\nu)+\int_{0}^{\infty} T(z) \alpha_{\nu}(z) \cdot L_{\nu}(z, \infty) d z \\
& \quad+L_{\nu}(0, \infty) \cdot\left(1-\epsilon_{S}(\nu)\right) \int_{0}^{\infty} T(z) \alpha_{\nu}(z) L_{\nu}(0, z) d z,
\end{aligned}
$$

where the first term on the tight hand side is the surface contribution to the total brightness temperature received by a downward looking radiometer. The second term is the upwelling radiation of the atmosphere and the last term is the downwelling radiation of the atmosphere reflected from the earth's surface and attenuated by the intervening atmosphere.

$$
L_{\nu}\left(z_{1}, z_{2}\right)=\exp \left[-\int_{z_{1}}^{z_{2}} \alpha_{\nu}(z) d z\right],
$$

where $L_{v}\left(z_{1}, z_{2}\right)=$ transmittance, $\alpha_{v}(z)=$ total absorption at altitude $z, \epsilon_{\mathrm{g}}(\nu)$ $=$ emissivity of the surface $T_{s}=$ surface temperature $T(z)=$ temperature at altitude $z$.

In computing the total brightness temperature, computations of oxygen absorptions were performed using the latest model provided by Rosenkranz (1975) which enables to provide oxygen absorption up to 1 millibar level.

For a particular state of the atmosphere the results of the computations with various components show (table 1) that most of the contribution to the brightness temperature comes from the upwelling radiances, i.e. second term in equation (1). Therefore, (1) can be rewritten as

$$
T_{\mathbf{B}}(\nu) \approx \int_{0}^{\infty} T(z) W_{\nu}(z) d z,
$$

where $W_{v}(z)=\alpha v(z) L_{r}(z, \infty)$ and is called the weighting function and decides the contribution of each layer of the atmosphere to the total brightness temperature. Figure 1 shows the plot of $W_{v}(z)$ with altitude for MSU channels for a typical atmosphere and makes it clear that individual frequency senses individual altitudes of the atmosphere most significantly but the peaks are not well defined. This broadening of the weighting function peaks suggests a combination of total brightness temperature retrieval.

\subsection{Method}

The mathod of deriving temperature profile used in the present investigation is essentially a regression analysis of atmospheric temperature profiles and 
numerically calculated atmospheric emission and is similar to the statistical method described by Rodgers (1976) and Waters et al (1975).

Atmospheric temperature is represented by the vector $\mathbf{T}$ whose elements give the temperatures at discrete levels. This temperature vector is related to a vector function of the numerically calculated brightness temperature $\phi\left(T_{\mathrm{B}}\right)$ by a matrix $D$. Mathematically,

$$
T=D \cdot \phi\left(T_{\mathrm{B}}\right) \text {. }
$$

Table 1. Computation of thermal microwave radiation received by a downward looking radiometer for a typical tropical atmosphere for MSU channels.

\begin{tabular}{llccc}
\hline $\begin{array}{c}\text { Frequency } \\
\text { GHz }\end{array}$ & $\begin{array}{c}\text { Total } \\
\text { transmittance }\end{array}$ & $\begin{array}{c}\text { Upwelling } \\
\text { radiation } \\
{ }^{\circ} \mathrm{K}\end{array}$ & $\begin{array}{c}\text { Downwelling } \\
\text { radiation } \\
{ }^{\circ} \mathrm{K}\end{array}$ & $\begin{array}{c}\text { Total } \\
\text { brightness } \\
\text { temperature } \\
{ }^{\circ} \mathrm{K}\end{array}$ \\
\hline 53.74 & $9.47 \times 10-2$ & 233.99 & 259.55 & 260.63 \\
54.96 & $2.33 \times 10^{-3}$ & 232.99 & 29295 & 233.05 \\
57.95 & $8.20 \times 10^{-12}$ & 201.59 & 299.60 & 201.59 \\
\hline
\end{tabular}

Expectation value of brightness temperature for MSU channels.

$$
\begin{aligned}
& 53.74 \mathrm{GHz}=259.71606^{\circ} \mathrm{K} \\
& 54.96 \mathrm{GHz}=231.12944^{\circ} \mathrm{K} \\
& 57.95 \mathrm{GHz}=201.91647^{\circ} \mathrm{K}
\end{aligned}
$$

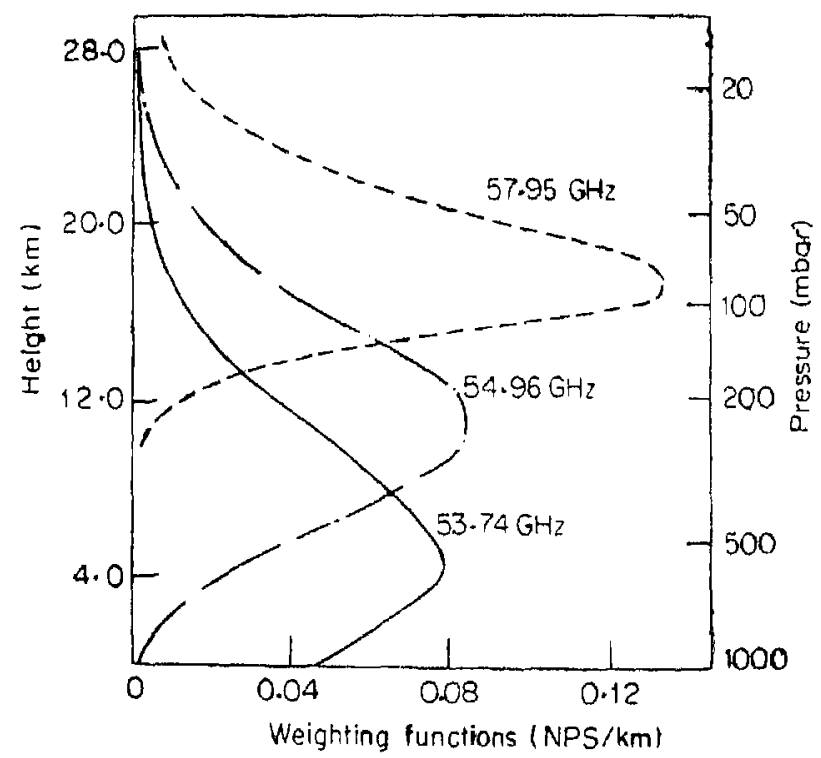

Figure 1. Weighting function of a typical tropical atmosphere for downward pointing radiometer for MSU channels. 
The measurement basis function $\phi\left(T_{\mathrm{B}}\right)$ vector, used for determining atmospheric temperature is

$$
\phi\left(T_{\mathrm{B}}\right)=\left\{\begin{array}{c}
T_{\mathrm{B} 1}-\overline{T_{\mathrm{B} 1}} \\
T_{\mathrm{B} 2}-\overline{T_{\mathrm{B} 2}} \\
T_{\mathrm{B} 3}-\widetilde{T_{\mathrm{B} 3}}
\end{array}\right\}
$$

where $T B_{\mathrm{n}}$ is the calculated brightness temperature for $n$ channels and the overbar denotes the expectation value. Non-linear terms are not included in the basis function vector as they contribute a negligible amount to the inferred temperature (Waters et al 1975). The matrix $D$ is chosen to minimise the expected error between the determined profile and actual temperature and is given by

$$
D=C(T, \phi) C^{-1}(\phi, \phi)
$$

where $C$ is a correlation matrix and is calculated from atmospheric statistics.

In the present analysis matrix $D$ has been calculated for the grid $\left(0^{\circ}-8^{\circ} \mathrm{N}\right.$, $45^{\circ}-80^{\circ} \mathrm{E}$ ) for the period A.pril to June 1979 (table 2). In computing the regression coefficients, MONEX-79 ship data were used. Only those data were taken into consideration which gave temperature up to $50 \mathrm{mb}$ pressure level or less than this pressure value. Then these data were interpolated and used for simulations.

Table 2. Regression coefficients derived for region $0^{\circ}-8^{\circ} \mathrm{N}, 45^{\circ}-80^{\circ} \mathrm{E}$ for the

\begin{tabular}{|c|c|c|c|c|}
\hline Pressure & $d_{0}$ & $d_{1}$ & $d_{2}$ & $d 3$ \\
\hline 950.0 & 300.40454102 & 1.31722355 & -0.61153585 & -0.04996391 \\
\hline 900.0 & 294.70629883 & 1.20999718 & -0.45387328 & 0.25343800 \\
\hline 850.0 & 291.82031250 & 1.44716358 & -0.63146305 & 0.26674247 \\
\hline 800.0 & 289.00634766 & 1.18411064 & -0.29013276 & 0.13350242 \\
\hline 750.0 & 286.44897461 & 1.42591381 & -0.32995629 & 0.10776657 \\
\hline 700.0 & 283.36328125 & 1.99808979 & -0.53337455 & 0.07096279 \\
\hline 650.0 & 279.65600586 & 1.92309093 & -0.66738880 & 0.10499465 \\
\hline 600.0 & 275.81323242 & 2.12315750 & -1.18764782 & 0.10497957 \\
\hline 550.0 & 271.72753906 & 2.12751770 & -1.43130302 & 9.14793032 \\
\hline 500.0 & 267.70605469 & 1.88169193 & -0.90766722 & 0.09776342 \\
\hline 450.0 & 263.36328125 & 2.26181126 & -1.27892208 & $0.2743886 ?$ \\
\hline 400.0 & 257.91333008 & 1.69935513 & -0.75683600 & 0.20848846 \\
\hline 350.0 & 251.39958191 & 1.71650219 & -0.24601322 & -000788214 \\
\hline 3000 & 243.20683289 & 0.88005757 & 0.02176391 & -0.09028620 \\
\hline 250.0 & 233.47836304 & 0.34978378 & 0.25134903 & -0.03952964 \\
\hline 200.0 & 221.48559570 & -0.59166765 & 1.06930733 & -0.23168111 \\
\hline 150.0 & 207.64985657 & -0.55813849 & 1.16644382 & $-0,04486612$ \\
\hline 50.0 & 205.18553162 & 0.69016749 & -1.19312000 & 0.43513966 \\
\hline
\end{tabular}
period April to June 1979.

$\widetilde{T_{\mathrm{B}}}(53.74)=259.72, \widehat{T_{\mathrm{B}}}(54.96)=231.13, \bar{T}_{\mathrm{B}}(57.95)=201.92$. 


\section{Results and discussions}

The sample spots of TIROS-N data of October 11, 1979 (Pass No. 15119) at 10 GMT over four Indian radiosonde stations have been analysed. The sub-satellite track, cross-track scan and locations of the four radiosonde stations are shown in figure 2. The temperature profile obtained from MSU data, with author's regression coefficients alongwith 12 GMT radiosonde temperature profiles are shown graphically in figures 3-6 for the four radiosonde stations Trivandrum, Cochin, Madras and Hyderabad. It is clear from figures 3 to 6 that temperature profiles (except Hyderabad) obtained from present coefficients are closer to radiosonde profiles than those derived from NOAA coefficients.

Also the deviations from radiosonde temperatures in both temperatures (present and NOAA) are shown graphically in figures 7 to 8 alongwith the r.m.s. deviations for all the four stations. The discrepancy (maximum at Hyderabad) between the radiosonde and author's derived temperature profiles suggests the derivation of regional coefficients season-wise.

Another reason for the discrepancy might be due to the fact that satellite measurement is an average over area $(100 \mathrm{~km} \times 100 \mathrm{~km})$ while radiosonde is a point measurement, and the radiosonde data density is not high for that region sensed by satellite. It is proposed to obtain regression coefficient sets for relatively small regions and for various seasons.

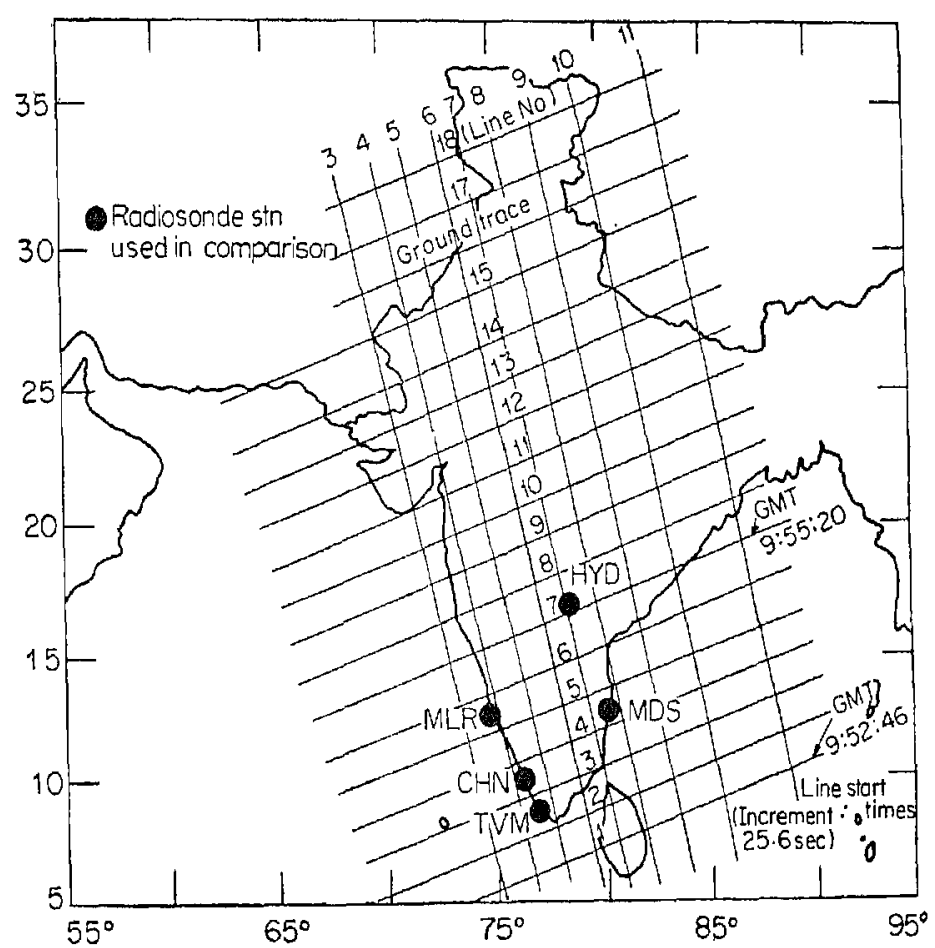

Figure 2. MSU-earth locations pass 15119 11-10-79. 


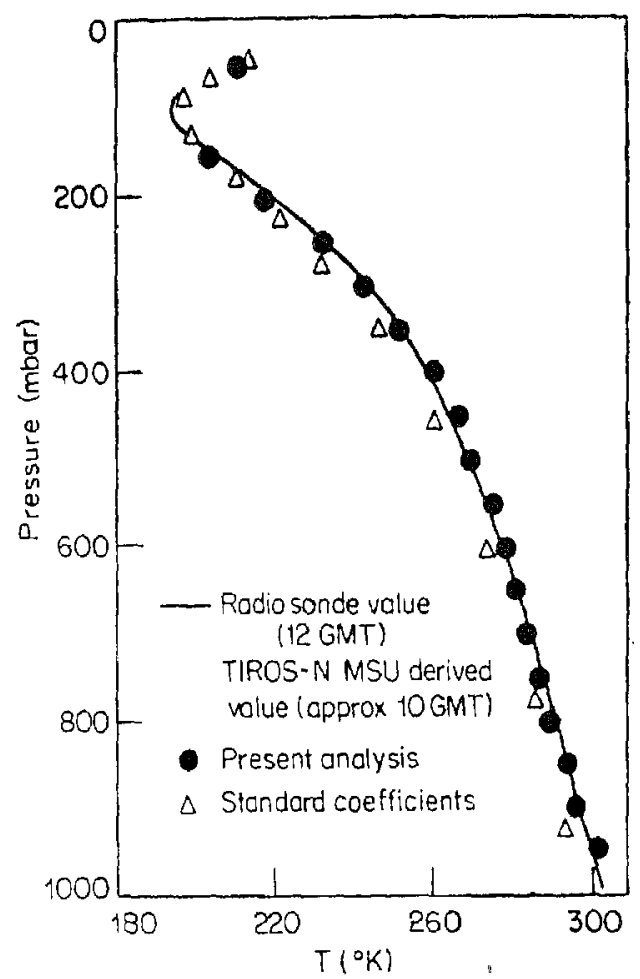

Figure 3. MSU - radiosonde comparison over Trivandrum on 11-10-79 pass no. 15119.

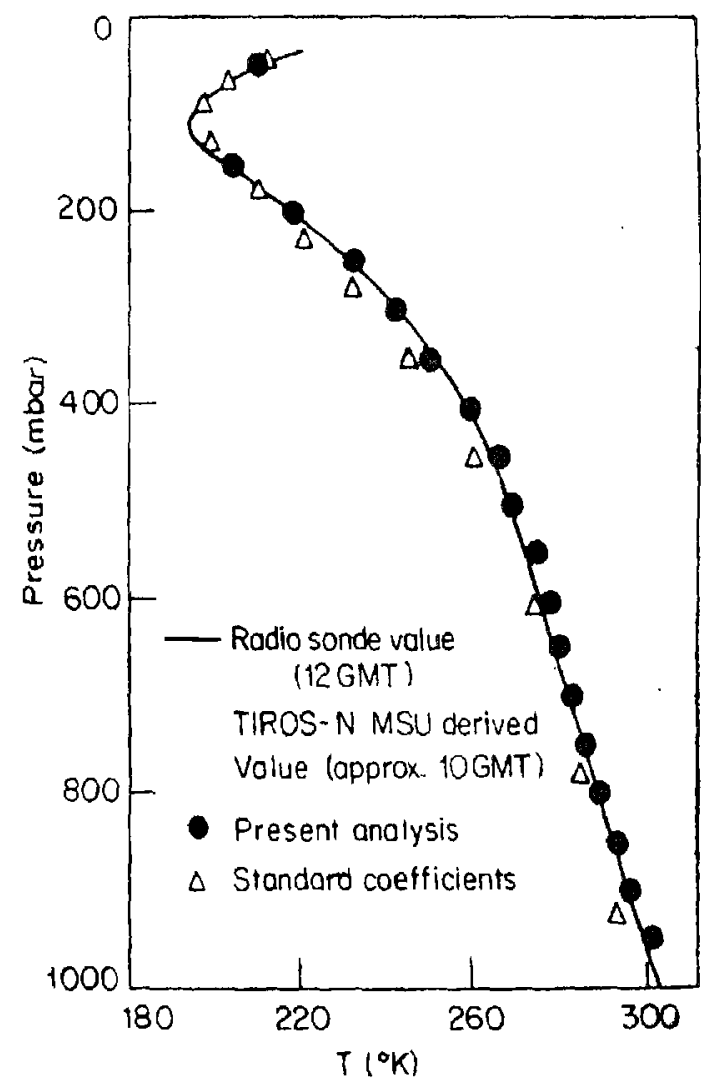

Figure 4. MSU - radiosonde comparison over Cochin on 11-10-79, pass no. 15119. 


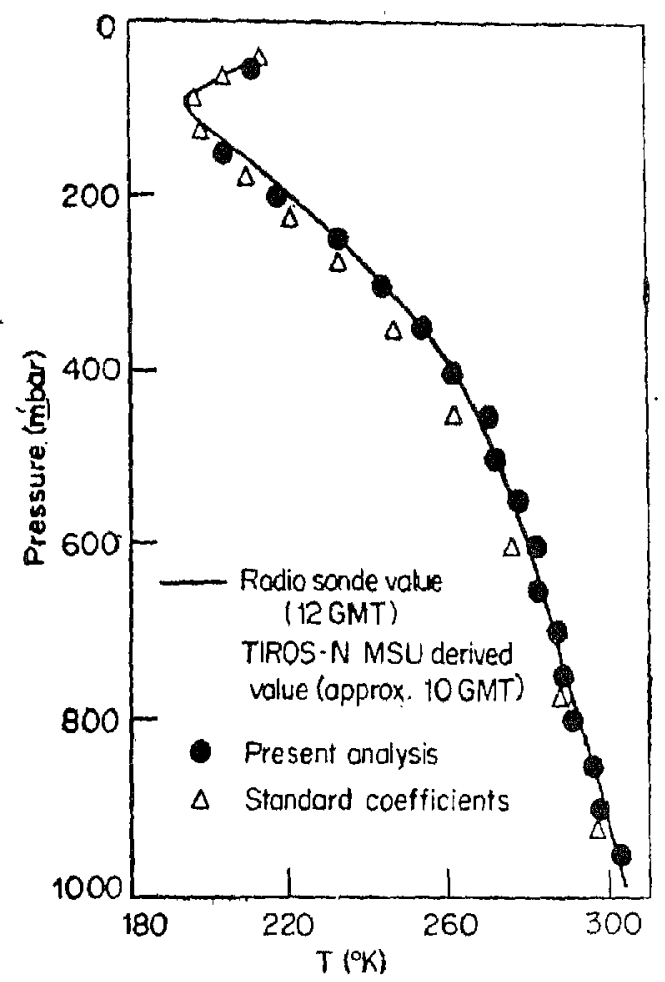

Figure 5. MSU - radiosonde comparison over Madras on 11-10 79, pass no. 15119.

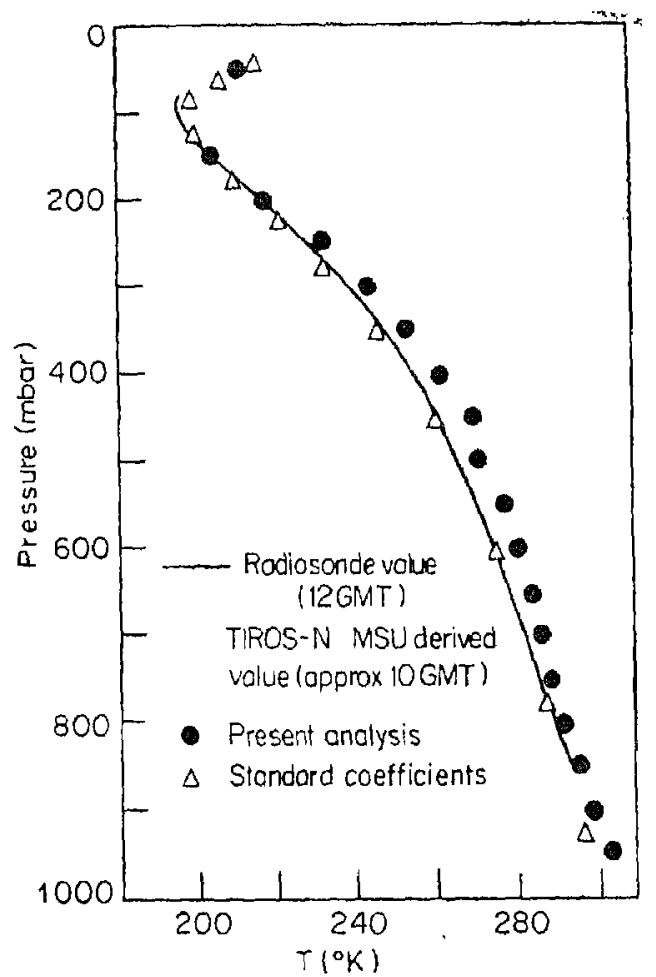

Figure 6. MSU - radiosonde comparison over Hyderabad on 11-10-79, pass no. 15119. 


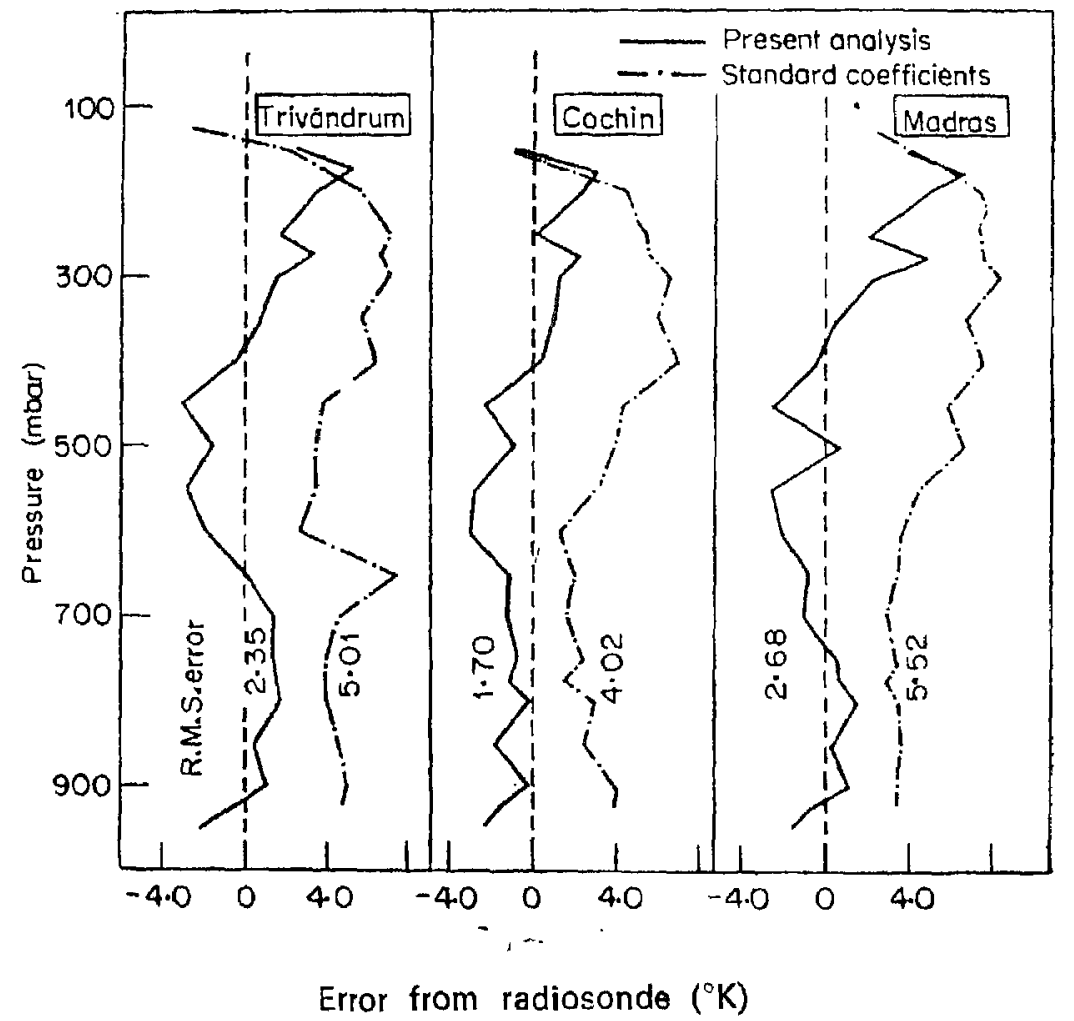

Figure 7. Comparison of errors from radiosonde.

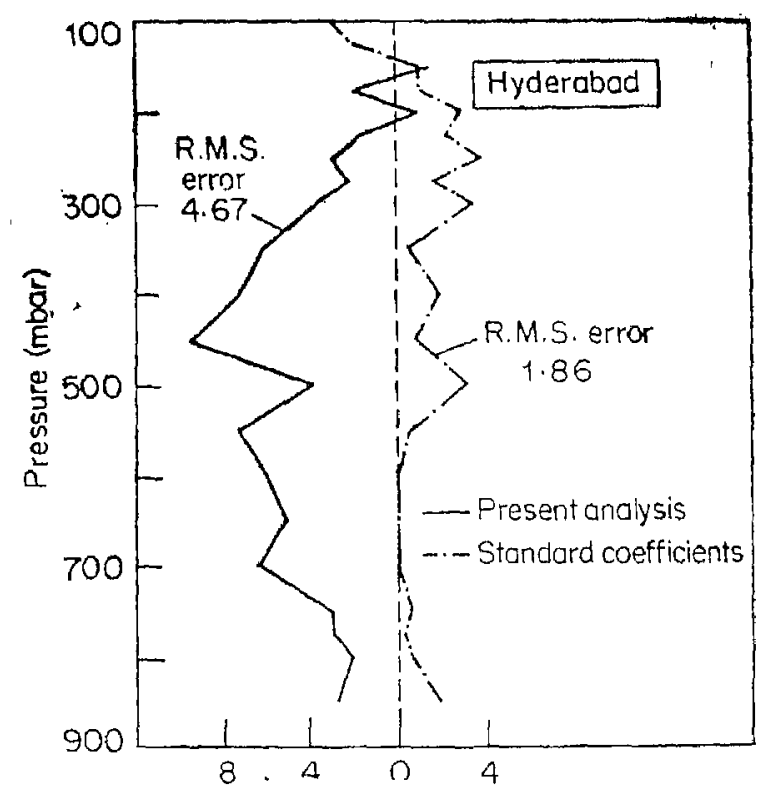

Error from radiosonde $\left({ }^{\circ} \mathrm{K}\right)$

Figure 8. Comparison of errors from radiosonde. 
Acknowledgement

The authors are grateful to Dr T A Hariharan, Head, Meteorology Division for his useful guidance and encouragement. Thanks are also due to Professor Yash Pal, Space Applications Centre, for his appreciation and suggestions. The authors are grateful to Dr Pranav Desai Ifor suggesting the problem. Critical comments from Dr M S Narayanan and Dr VK Agarawal, Meteorology Division are appreciated and acknowledged.

The TIROS data used in this study were recorded at ISTRAC/SHAR and made available to Met. Division, SAC for which the authors thank Shri N Pant, SHAR and Manager, Deputy Manager and staff of ISTRAC.

\section{References}

NOAA Tech. Meno. 1978 (March) The TIROS-N/NOAA A. G. series of Satellites, NESS-95

NOAA 1978 (Oct.) 'Meteorological interpretation of TIROS-N MSU Data. Memo by staff, Mesoscale Applications Branch

NOAA Tech. Memo 1979 (July) Techniques for data extraction and calibration of TIROS-N] NOAA series of radiometers for direct readout users, NESS-107

Rodgers C D 1976 (November) Rev. Geophys. and Space Phys, 14 609-624

Rosenkranz P W 1975 IEEE Trants. Ant. Prop. AP 23 498-506

Waters J W, Kunzi K F, Pettyjohn R L, Poon R K L and Staelin D H 1975 J. At. Sci. 32 1953-1969 